\title{
Reconocimiento de autoría en un simposio publicado en Gaceta Médica de México
}

\section{Manuel Urbina-Fuentes}

Academia Nacional de Medicina, Comité Permanente para el Estudio de los Determinantes Sociales de la Salud, Ciudad de México, México

En el número 6 de 2017, páginas 697-730, de Gaceta Médica de México, se publicó el simposio "La transición de los Objetivos de Desarrollo del Milenio a los Objetivos de Desarrollo Sostenible desde la perspectiva de los determinantes sociales de la salud y la equidad en salud".

En los autores, quien suscribe omitió de manera involuntaria el nombre de la doctora Abish Romero, del Instituto Nacional de Salud Pública. La lista completa es la siguiente: Manuel Urbina Fuentes, Luis Jasso Gutiérrez, Rafaela Schiavon Ermani, Rafael Lozano, Abish Romero y Jacobo Fikelman.

Reconozco que esta comunicación se realizó posterior a la publicación impresa y electrónica en su versión en español, por lo cual el documento ya no es modificable. 